\title{
Preferences of women for web-based nutritional information in pregnancy
}

\author{
Rachel AK Kennedy \\ Technological University Dublin, rachel_kennedy@live.ie \\ Laura Mullaney \\ Technological University Dublin \\ C.M.E. Reynolds \\ University College Dublin
}

See next page for additional authors

Follow this and additional works at: https://arrow.tudublin.ie/scschbioart

Part of the Maternal and Child Health Commons, Public Health Education and Promotion Commons, and the Women's Health Commons

\section{Recommended Citation}

R.A.K. Kennedy, L. Mullaney, C.M.E. Reynolds, S. Cawley, D.M.A. McCartney, M.J. Turner, Preferences of women for web-based nutritional information in pregnancy, Public Health, Volume 143, 2017, Pages 71-77, ISSN 0033-3506, DOI: 10.1016/j.puhe.2016.10.028.

This Article is brought to you for free and open access by the School of Biological Sciences at ARROW@TU Dublin. It has been accepted for inclusion in Articles by an authorized administrator of ARROW@TU Dublin. For more information, please contact arrow.admin@tudublin.ie, aisling.coyne@tudublin.ie,gerard.connolly@tudublin.ie.

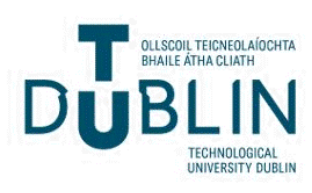




\section{Authors}

Rachel AK Kennedy, Laura Mullaney, C.M.E. Reynolds, S. Cawley, Daniel McCartney, and M.J. Turner 


\title{
Original Research
}

\section{Preferences of women for web-based nutritional information in pregnancy}

\author{
R.A.K. Kennedy ${ }^{a,{ }^{*},}$, L. Mullaney ${ }^{a}$, C.M.E. Reynolds ${ }^{b}$, S. Cawley ${ }^{a}$, \\ D.M.A. McCartney ${ }^{a}$, M.J. Turner ${ }^{b}$ \\ ${ }^{a}$ School of Biological Sciences, Dublin Institute of Technology, Kevin Street, Dublin 8, Ireland \\ ${ }^{\mathrm{b}}$ UCD Centre for Human Reproduction, Coombe Women and Infants University Hospital, Dublin 8, Ireland
}

\section{A R T I C L E I N F O}

\section{Article history:}

Received 5 April 2016

Received in revised form

21 October 2016

Accepted 24 October 2016

Available online 1 December 2016

Keywords:

Maternal

Nutrition

Fetal programming

Web-based

\begin{abstract}
A B S T R A C T
Objectives: During pregnancy, women are increasingly turning to web-based resources for information. This study examined the use of web-based nutritional information by women during pregnancy and explored their preferences.

Study design: Cross-sectional observational study.

Methods: Women were enrolled at their convenience from a large maternity hospital. Clinical and sociodemographic details were collected and women's use of web-based resources was assessed using a detailed questionnaire.

Results: Of the 101 women, $41.6 \%$ were nulliparous and the mean age was 33.1 years (19-47 years). All women had internet access and only $3 \%$ did not own a smartphone. Women derived pregnancy-related nutritional information from a range of online resources, most commonly: What to Expect When You're Expecting (15.1\%), Babycenter (12.9\%), and Eumom (9.7\%). However, $24.7 \%$ reported using Google searches. There was minimal use of publically funded or academically supported resources. The features women wanted in a web-based application were recipes $(88 \%)$, exercise advice $(71 \%)$, personalized dietary feedback (37\%), social features (35\%), videos $(24 \%)$ and cooking demonstrations $(23 \%)$.

Conclusions: This survey highlights the risk that pregnant women may get nutritional information from online resources which are not evidence-based. It also identifies features that women want from a web-based nutritional resource.
\end{abstract}

(C) 2016 The Royal Society for Public Health. Published by Elsevier Ltd. All rights reserved.

\section{Introduction}

Maternal nutrition during pregnancy influences the long-term health outcomes of both the woman and her offspring. ${ }^{1,2}$ Suboptimal maternal nutrition may result in unfavourable neonatal outcomes, such as fetal growth restriction and neural tube defects. It may also increase the risk of long-term adverse metabolic profiles later in life. ${ }^{3-6}$ Research has shown that women are not meeting intake recommendations for key micronutrients in pregnancy such as iron (12.5\% compliance),

* Corresponding author. UCD Centre for Human Reproduction, Coombe Women and Infants University Hospital, Dublin 8, Ireland. Fax: +35314085760.

E-mail address: rachel_kennedy@live.ie (R.A.K. Kennedy). 
vitamin D (0.3\% compliance), iodine (50.5\% compliance) and folate (2.1\% compliance). ${ }^{7}$ Furthermore, dietetic services and personnel to deliver dietetic advice are an increasingly constrained resource. ${ }^{8}$ In 2014, the Coombe Women and Infants University Hospital (CWIUH) provided dietetic care to just over $25 \%$ of women attending the hospital, with many patients seen in group format as the hospital is limited to 1.0 wholetime equivalent (WTE) dietitian. ${ }^{9}$

Web-based technology is a widely accessible and cost effective means of disseminating information to large populations. A systematic review identified web-based technology as a safe and potentially efficacious dietetic tool in pregnancy, although this study cited the need for further supportive data in this area. ${ }^{10}$ Studies have also reported high attrition rates which might compromise the overall utility of such tools, and which highlight the requirement to determine what features could improve user retention. ${ }^{11}$ The increasing evidence supporting the importance of maternal diet in pregnancy, as well as the potential efficacy of web-based tools to deliver evidence-based dietetic interventions, suggest that research in this area is warranted.

Optimal methods of delivering evidence-based nutrition information which engages obstetric populations need to be defined. There is a lack of knowledge to date concerning the features of web-based applications which pregnant women find useful. Furthermore, what evidence-based information pregnant women find interesting and engaging also needs to be determined.

The purpose of this observational study was to examine the use of web-based nutritional information by women attending for prenatal care in a large academic maternity hospital in a developed country.

\section{Methods}

A self-administered, paper-based questionnaire was distributed to women attending for antenatal care after confirmation of a healthy, ongoing pregnancy at the CWIUH between June 2015 and August 2015. Women were recruited from booking and antenatal clinics at varying stages of gestation. The CWIUH accepts patients from all socioeconomic groups, and from across the urban-rural divide. It is one of the largest maternity hospitals in the European Union (EU). In 2014, the hospital delivered over 8,800 infants $\geq 500$ g. ${ }^{9}$ Informed consent was obtained from all participants. Women who did not understand English were excluded from the study.

The questionnaire was categorized into three sections. Section one contained questions relating to participant characteristics, including age, parity, health insurance cover, internet access and smartphone ownership.

Section two of the questionnaire collected information on women's use of web-based technologies and their preferences in this area. Questions and their response options were generated by clinical and research dietitians and adapted from previous surveys. ${ }^{12,13}$ Participants were asked if they sought nutritional advice and if so, the sources they used. Respondents were given a multi-option list of ten possibilities, with the addition of a free text box to list additional options or state which specific resources they used.
In addition, data describing the features respondents would like in an online pregnancy nutrition tool were collected. A multi-option question with seven possibilities was provided, and a free text box to list additional features.

Participants were asked further questions concerning: i) their general use of downloadable pregnancy applications for mobile devices (apps), websites or fora; ii) their use of pregnancy apps, websites or fora to source nutritional advice and finally; iii) whether or not they would use an online resource for nutrition advice during their pregnancy. These questions were dichotomous 'Yes'/'No' options to determine participants' usage, followed by a free text box asking participants to provide further information. Factors which would prevent respondents from using an online pregnancy nutrition tool were also collected. A list of four possible options was available, with a free text box to list additional barriers.

Section three of the questionnaire collected information on socioeconomic status using questions derived from the EU Survey on Income and Living Conditions. ${ }^{14}$ Relative income poverty status was determined by comparing equivalized household income against the $60 \%$ national median income threshold. Relative deprivation status was assessed by determining whether the respondents had experienced the enforced absence (due to financial constraint) of two or more basic necessities from a list of eleven over the past year. Respondents whose equivalized household income fell below the relative income poverty threshold, in addition to experiencing the enforced absence of two or more of the eleven basic markers of deprivation were deemed to be living in consistent poverty. Participants' level of formal educational attainment was also collected.

The study sample size was based on a previous surveybased cross-sectional observational study, using convenience recruitment. This study assessed internet use among pregnant women and calculated a required sample size of 100 women. ${ }^{15}$ Data were analysed using IBM SPSS statistics version 22.0 (IBM Corporation, Armonk, New York). Any missing data were coded as missing before analysis. The included sample for each analysis is reported in the results table and is denoted in the footnote of the relevant table. Continuous variables were collapsed into categorical variables, including age ( $<30 \mathrm{vs} \geq 30$ years) and parity (nulliparous vs multiparous) to differentiate preferences amongst older and younger mothers and between first and second time mothers, respectively. ${ }^{15}$

Descriptive statistics were used to describe participant characteristics and participant questionnaire responses. Differences in categorical variables between groups [age (<30 vs $\geq 30$ years), parity (nulliparous vs multiparous), health insurance cover (public vs private) and educational level ( $<$ third level vs $\geq$ third level)] were analysed using cross-tabulation with chi-squared tests for independence. Several binary logistic regression models analysing the association between women's demographic and socioeconomic status and the features they want in a web-based nutrition tool were performed. In all statistical analyses, a $P$ value of $<0.05$ was considered statistically significant. This study received ethical approval from the CWIUH Research Ethics Committee and the Dublin Institute of Technology Research Ethics Committee. 


\section{Results}

A total of 110 questionnaires were distributed and 101 (91.8\%) of these were returned. The study population characteristics are outlined in Table 1. There were no differences in age, parity or health insurance cover between our study population and the hospital population $(P>0.05) .{ }^{9}$ For the calculation of socioeconomic status, 62 of the 101 women provided data on income and deprivation status, which are required to calculate consistent poverty. Individuals can be reluctant to disclose their income, and furthermore, may not know or remember their exact income. ${ }^{16,17}$

Of the women surveyed, $100 \%(n=101)$ reported having internet access, 97\% $(n=98)$ reported having a smartphone and $82.2 \%(n=83)$ reported using online pregnancy fora, websites or apps. A wide variety of online resources were cited, and $65.6 \%(n=61)$ of women reported using multiple (i.e. more than one) web-based resources for pregnancy-related nutritional advice.

The majority of participants $(87.1 \%, n=88)$ reported that they would use a nutrition app or website during their pregnancy; whereas $9.9 \%$ of participants $(n=10)$ reported that they

\section{Table 1 - Participant characteristics $(n=101)$.}

\begin{tabular}{|c|c|}
\hline \multicolumn{2}{|l|}{ Age $^{a}$} \\
\hline Age (years; mean [SD]) & $33.1(4.97)$ \\
\hline Age (years; range) & $19-47$ \\
\hline \multicolumn{2}{|l|}{ Parity } \\
\hline Nulliparous ( $n[\%])$ & $42(41.6 \%)$ \\
\hline \multicolumn{2}{|l|}{ Patient health insurance $b$} \\
\hline Private $(n[\%])$ & $33(32.7 \%)$ \\
\hline Public (n [\%]) & $67(66.3 \%)$ \\
\hline \multicolumn{2}{|l|}{ Socioeconomic status } \\
\hline Relative deprivation $^{\mathrm{c}}(\mathrm{n},[\%])$ & $16(15.8 \%)$ \\
\hline Relative income poverty ${ }^{\mathrm{d}}(\mathrm{n}[\%])$ & $8(7.9 \%)$ \\
\hline Consistent poverty $(n[\%])$ & $6(5.9 \%)$ \\
\hline \multicolumn{2}{|l|}{ Internet access } \\
\hline Yes $(n[\%])$ & $101(100 \%)$ \\
\hline \multicolumn{2}{|l|}{ Smartphone owner } \\
\hline Yes $(n[\%])$ & $98(97 \%)$ \\
\hline \multicolumn{2}{|l|}{ Education level $^{\mathrm{f}}$} \\
\hline Lower secondary ( $n[\%])$ & $2(2 \%)$ \\
\hline Upper secondary $(n[\%])$ & $22(21.8 \%)$ \\
\hline Technical or vocational qualification (n $[\%]$ ) & $4(4 \%)$ \\
\hline Third level: non-degree ( $[\%])$ & $14(13.9 \%)$ \\
\hline Primary degree $(n[\%])$ & $13(12.9 \%)$ \\
\hline $\begin{array}{l}\text { Professional qualification of at least degree status } \\
\text { (n [\%]) }\end{array}$ & $6(5.9 \%)$ \\
\hline Postgraduate degree $(n[\%])$ & $12(11.9 \%)$ \\
\hline Doctorate $(\mathrm{PhD})(n[\%])$ & $2(2 \%)$ \\
\hline \multicolumn{2}{|l|}{ Health status } \\
\hline $\begin{array}{l}\text { Pre-existing diabetes/gestational diabetes mellitus } \\
{[n(\%)]}\end{array}$ & $9(9 \%)$ \\
\hline Pre-existing health conditions ${ }^{\mathrm{g}}(\mathrm{n}[\%])$ & $35(34.7 \%)$ \\
\hline \multicolumn{2}{|l|}{ a Data for $n=99$} \\
\hline \multicolumn{2}{|l|}{ b Data for $n=100$. } \\
\hline \multicolumn{2}{|l|}{${ }^{c}$ Data for $n=100$. } \\
\hline \multicolumn{2}{|l|}{ d Data for $n=62$} \\
\hline \multicolumn{2}{|l|}{ Data for $n=62$} \\
\hline f Data for $n=94$ & \\
\hline
\end{tabular}

would not use a nutrition app or website, and 3\% of participants $(n=3)$ did not answer this question. The primary reason reported for using a pregnancy-related nutrition app or website was to obtain accurate information on what is safe and healthy during pregnancy $(34.7 \%, n=35)$. This was followed by obtaining accessible, convenient and transportable information i.e. accessible via a smartphone or other portable device $(28.7 \%, n=29)$.

Factors which participants reported would prevent them from using a nutrition app or website included lack of time $(31.0 \%, n=31)$, not having internet access $(17.0 \%, n=17)$, lack of interest $(11.0 \%, n=11)$ and concerns in relation to anonymity $(6.0 \%, n=6)$. These findings did not differ by age, parity, socioeconomic status, health insurance status or educational level.

Table 2 outlines the online pregnancy resources (websites, apps and so forth) used by participants. Table 3 outlines the apps, websites and fora which participants used to find nutrition advice for pregnancy. Notably, 24.7\% $(n=23)$ reported using general Google searches to obtain information and did not indicate a preference for specifically evidencebased online resources. There was minimal use of academically supported or publically funded sources (e.g. HSE.ie).

Table 4 outlines the features which participants like about the apps they currently use. Previous research found $40 \%$ of women in pregnancy would like a nutrition app; therefore, we wished to further evaluate women's preferences in this area. ${ }^{13}$ These preferences did not vary according to age, parity, socioeconomic status, health insurance status or educational level.

Table 5 outlines the features which participants would most like to see in a web-based nutrition intervention for pregnancy. Of the participants aged 30 years and older, 75.9\% ( $n=60 / 79$ ) reported wanting exercise advice, compared with $50 \%(n=11 / 22)$ of those aged less than 30 years $(P=0.019)$. Amongst nulliparous mothers, 35.7\% ( $n=15 / 42)$ reported wanting video features, compared with $15.3 \%(n=9 / 59)$ of multiparous participants $(P=0.017)$. This relationship persisted when age was controlled for through binary logistic regression $(P=0.02)$. Amongst the participants with private health insurance cover, $64.4 \%(n=13 / 19)$ wanted personalized dietary feedback compared with $29.6 \%(n=24 / 81)$ of participants with public health insurance cover $(P=0.002)$.

Of the participants with a third level educational qualification or higher, $92.4 \%(n=61 / 66)$ wanted recipes, compared with only $75 \%(n=21 / 28)$ of those without a third level

Table 2 - Pregnancy apps used by participants $(\boldsymbol{n}=\mathbf{9 4})$.

\begin{tabular}{llc} 
Pregnancy apps & $n$ & $\%$ of cases \\
\hline What to expect when you're expecting & 25 & $26.6 \%$ \\
Babycenter & 22 & $23.4 \%$ \\
Eumom & 12 & $12.8 \%$ \\
Rollercoaster & 9 & $9.6 \%$ \\
The Bump & 2 & $2.1 \%$ \\
Other & 20 & $21.3 \%$ \\
Not applicable & 18 & $19.1 \%$ \\
Not answered & 13 & $13.8 \%$ \\
\hline a Multiple response option. & \\
\hline
\end{tabular}


Table 3 - Apps, websites and fora which participants used to find nutrition advice for pregnancy $(\boldsymbol{n}=\mathbf{9 3})$.

\begin{tabular}{llc} 
Apps, websites and fora & $n$ & $\%$ of cases \\
\hline Google/internet search & 23 & $24.7 \%$ \\
What to expect when you're expecting & 14 & $15.1 \%$ \\
Babycenter & 12 & $12.9 \%$ \\
EUmom & 9 & $9.7 \%$ \\
NHS website & 5 & $5.4 \%$ \\
Rollercoaster & 3 & $3.2 \%$ \\
The Bump & 3 & $3.2 \%$ \\
First 1000 days & 2 & $2.2 \%$ \\
Pregnancy plus & 2 & $2.2 \%$ \\
Other & 24 & $25.8 \%$ \\
Not applicable (do not use) & 32 & $34.4 \%$ \\
\hline${ }^{a}$ Multiple response option. & & \\
\hline
\end{tabular}

Table 4 - The most favoured features in apps currently used by participants $(n=101)$.

\begin{tabular}{llc} 
Features & $n$ & $\%$ of cases \\
\hline Social features (e.g. group discussion fora) & 18 & $17.8 \%$ \\
Informative & 13 & $12.9 \%$ \\
Information on pregnancy & 12 & $11.9 \%$ \\
Ease of use/convenience & 10 & $9.9 \%$ \\
Ability to track fetal development & 5 & $5 \%$ \\
Music and relaxation & 3 & $3 \%$ \\
Non pregnancy specific tracking features & 2 & $2 \%$ \\
Not applicable (did not use an app(s)) & 7 & $6.9 \%$ \\
Not answered & 34 & $33.7 \%$ \\
\hline${ }^{2}$ Multiple response option. & \\
\hline
\end{tabular}

education $(P=0.02)$. Of those with a third level qualification, $51.5 \%$ ( $n=34 / 66$ ) wanted personalized dietary feedback, compared with $7.1 \%(n=2 / 28)$ of those with no third level education $(P<0.001)$. Furthermore, $45.5 \%(n=30 / 66)$ of those with a third level education wanted social features such as a group discussion fora; compared with $14.3 \%(n=4 / 28)$ of those

Table 5 - Features participants would most like to see in a web-based nutrition intervention $(n=97)$.

\begin{tabular}{lll} 
Features & $n$ & $\begin{array}{c}\% \\
\text { cases }^{\mathrm{a}}\end{array}$ \\
\hline Recipes & 88 & $88 \%$ \\
Exercise advice & 71 & $71 \%$ \\
Personalised dietary feedback & 37 & $37 \%$ \\
Social features (e.g. group discussion fora) & 35 & $35 \%$ \\
Videos & 24 & $24 \%$ \\
Cooking demonstrations & 23 & $23 \%$ \\
Quizzes & 9 & $9 \%$ \\
Other & 11 & $10.9 \%$ \\
Other specified as: & & \\
Forum moderated by a dietitian & 2 & $2 \%$ \\
Meal plans, shopping lists & 2 & $2 \%$ \\
Food tracker & 1 & $1 \%$ \\
Nutrition advice in pregnancy & 4 & $4 \%$ \\
Advice specific to medical conditions during & 2 & $2 \%$ \\
$\quad$ pregnancy & & \\
\hline a Multiple response option. & & \\
\hline
\end{tabular}

with no third level education $(P=0.004)$. Finally, 35.7\% $(n=10$ / 28) of participants with a third level education wanted cooking demonstrations compared with $16.7 \%(n=11 / 66)$ of their less educated peers $(P=0.04)$.

Table 6 outlines logistic regression analyses describing the associations between women's socioeconomic status and the features they want in a web-based nutrition tool (model 1 recipes, model 2 dietary advice and model 3 social features) when age and parity are controlled for. Models run with cooking demonstrations as the dependent variable did not produce a worthwhile model for logistic regression (Omnibus test of model coefficient $>0.05$ and Hosmer Lemeshow Test $<0.05)$.

\section{Discussion}

We found that the majority of pregnant women irrespective of their sociodemographic and clinical circumstances used webbased resources for information on nutrition. However, they used a wide variety of resources, mainly commercial, with little use of publicly-funded or academically-supported resources which raises the possibility of them receiving conflicting or erroneous advice. We identified that women's preferences for content varied with age, health insurance cover and educational level, and therefore future web-based resource design should allow women to customize access to information according to their needs.

\section{Current use of online resources in pregnancy}

All women surveyed reported having internet access and $97 \%$ of women reported having a smartphone; engagement levels which are consistent with previous research. ${ }^{18,19}$ These results also indicate an increase in the proportion of pregnant women using smartphones from the $76 \%$ reported in a 2012-2013 survey conducted in the CWIUH. ${ }^{13}$

Research in a nutrition programme for women, infants and children $(n>8000)$ demonstrated decreased interest in one-toone nutritional information with a Health Care Professional (HCP) and increased interest in online education. ${ }^{19}$ Furthermore, a study on the use of apps in dietetic practice $(n=139)$ found that nearly half of the dietitians surveyed had a patient ask about or use a nutrition/food-related app. ${ }^{20}$ These findings demonstrate the emerging role for such technologies in dietetic practice.

\section{Credibility of information obtained from online resources}

Disconcertingly, our results indicate that there is minimal use of publically funded or academically supported resources; therefore, women may obtain nutritional information that is not scientifically-derived and may vary from current evidence-based guidelines. ${ }^{21}$ Our study highlighted that $24.7 \%$ of women use general Google searchers to obtain information. This may indicate that women are not seeking evidence based sites specifically-rather they are favouring the most popular links provided as determined through the Google search engine. 
Table 6 - Logistic regression of socioeconomic factors associated with the features women want in a web-based nutrition tool.

\begin{tabular}{|c|c|c|c|c|c|c|c|}
\hline \multirow[t]{2}{*}{ Socioeconomic status } & \multirow[t]{2}{*}{$n$} & \multicolumn{2}{|c|}{ Model 1 recipes* } & \multicolumn{2}{|c|}{$\begin{array}{l}\text { Model } 2 \text { personalised } \\
\text { dietary advice* }\end{array}$} & \multicolumn{2}{|c|}{ Model 3 social features* } \\
\hline & & $\operatorname{Exp}(B)(95 \%$ CI $)$ & $P$ & $\operatorname{Exp}(B)(95 \%$ CI $)$ & $P$ & $\operatorname{Exp}(B)(95 \%$ CI $)$ & $P$ \\
\hline \multicolumn{8}{|l|}{ Education 3rd level } \\
\hline Yes & 66 & $11.94(2.1-68.3)$ & 0.005 & $14.1(2.5-81.4)$ & 0.003 & $6.43(1.64-25.1)$ & 0.007 \\
\hline No & 28 & 1.0 (Ref.) & & 1.0 (Ref.) & & 1.0 (Ref.) & \\
\hline \multicolumn{8}{|l|}{ Health insurance cover } \\
\hline Public & 67 & $3.887(0.68-22.1)$ & NS & $0.30(0.11-0.85)$ & 0.024 & $1.415(0.52-3.86)$ & NS \\
\hline Private & 33 & 1.0 (Ref.) & & 1.0 (Ref.) & & 1.0 (Ref.) & \\
\hline $\mathrm{X}^{2}$ ( $\mathrm{P}$ value $)$ & & $10.5(0.032)$ & & $25.2(<0.001)$ & & $11.1(0.025)$ & \\
\hline Coxs and snell $\mathrm{R}^{2}$ & & 0.106 & & 0.235 & & 0.111 & \\
\hline Negelkerke $\mathbf{R}^{2}$ & & 0.199 & & 0.320 & & 0.153 & \\
\hline
\end{tabular}

Individuals may lack the ability to critically appraise the accuracy and credibility of information provided in online resources. ${ }^{22-24}$ In a study which investigated the reliability of web-based medical advice, only $39 \%$ of the 500 sites examined provided correct information to answer the questions asked by users. $^{25}$ Furthermore, state-supported sites uniformly provided accurate medical information, highlighting the imperative to promote these resources to the public where they do exist.

\section{Differences in preferences among groups}

There is a paucity of evidence regarding the preferences of women for online nutrition resources in pregnancy. Our findings highlight differences in the preferences expressed between different groups of women, which may help alleviate the high-attrition rates observed in online health-based interventions. ${ }^{26,27}$

Although women were asked what features they would most like in an online nutrition tool, $71 \%$ of women identified exercise advice as a desirable feature. More women aged over 30 years reported wanting exercise advice $(P=0.019)$. Many women decrease their engagement in physical activity (PA) during pregnancy. ${ }^{28,29}$ However, research suggests that seeking PA advice online during pregnancy is associated with increased levels of activity. ${ }^{18}$ Supporting women with PA information in pregnancy may help to eradicate misconceptions in this area and may also improve engagement with and interest in PA advice within both age categories.

More nulliparous women reported wanting video features, compared with multiparous participants $(P=0.017)$. This relationship remained when age was controlled for through logistic regression $(P=0.02)$. These results may relate to perceived time constraints among the multiparous women; where they may feel that they do not have sufficient time available to watch video content.

In our study, marked differences in content preferences were seen between women with private and public health insurance cover. More women with private cover wanted personalized dietary advice compared with women with public cover $(P=0.002)$. This relationship persisted on multivariate analysis. All women attending for antenatal care (in the CWIUH) receive an antenatal pack containing a leaflet and booklet with dietary information. While some women may prefer this resource, $97 \%$ of lower socioeconomic status women reported general internet usage in a survey conducted at the CWIUH. ${ }^{13}$ This study also highlighted that women reported higher digital media resource use compared to traditional media resources.

Our findings may be reflective of results from previous research indicating that women of lower socioeconomic status have lower health control beliefs. ${ }^{30}$ These feelings of lack of control, coupled with difficulties such as financial constraint, may result in women feeling unable to implement dietary advice, or feeling that it will not benefit their health status. While women of lower socioeconomic status may not expect to receive dietary advice on a personalized level, these women demonstrate lower levels of interest in healthy eating advice, in addition to health advice for preventative purposes. $^{31,32}$ Women of lower socioeconomic status have also been found to prefer receiving advice in groups. ${ }^{32}$

The differences in content preferences expressed across the educational strata are also notable. Considerably, more of the women with third level education wanted recipes $(P=0.02)$, personalized dietary feedback $(P<0.001)$, social features $(P=0.004)$, compared with women who did not have third level education. These relationships persisted on multivariate analysis. Interestingly, more women who did not have third level education wanted cooking demonstrations compared to those with a third level qualification $(P=0.04)$. This may highlight a deficit in practical cooking skills which is more entrenched among women of low socioeconomic status. ${ }^{33}$ These insights may help future applications overcome the high attrition rates previously demonstrated by women with low levels of educational attainment. ${ }^{26}$

\section{Future work}

There is general enthusiasm for an online nutrition tool for pregnancy and their use in a clinical setting may broaden the capacity to disseminate evidence-based information and alleviate the pressure on already constrained dietetic resources. ${ }^{34,10}$ Despite this broad acceptability, future research is needed to determine how women are informed of sites 
during pregnancy, in addition to how web-based resources influence women's engagement levels and their behavioural change. There may also be benefit in exploring women's use of online resources for information on pre-existing health conditions. Robust research data are required to demonstrate the efficacy of such tools at the clinical interface.

\section{Strengths and limitations}

A strength of our study is that, to our knowledge, this is the first investigation to quantitatively assess the features which women would most like to use in an online nutrition resource during pregnancy. This may assist in the design of future online applications. A further strength of the study is that the questionnaire was semi-supervised. The researcher was available for clarification and provision of consistent information to all participants throughout completion of questionnaires, which minimized the potential for misinterpretation or lack of understanding of the questions asked.

A potential limitation of this study is that the single-centre, convenience sampling methodology used for recruitment could yield a cohort of participants who vary from the wider population, limiting the geralizability of our findings. Further potential limitations include the study's cross-sectional nature which precludes causal inferences being drawn; and selfselection bias whereby those who participated in the study may have been more interested in the research topic at hand than those who declined to participate. However, the CWIUH accepts women from all socioeconomic groups from across the urban-rural divide, and our post hoc analyses showed that the study population demographics did not differ from the hospital population in terms of age, parity of health insurance cover $(P>0.05){ }^{9}$

\section{Conclusion}

This study provides insights into the current preferences and practices of women attending for antenatal care in relation to online sources of nutritional information. It also articulates some of the specific features which could be developed to improve engagement with online nutrition interventions during pregnancy amongst different population groups. However, this study suggests that pregnant women use a variety of unregulated online resources when seeking nutritional information. This increases their risk of receiving dietary advice which is not scientifically based. There is therefore a need to develop engaging, customized and evidence-based online nutrition resources for pregnant women, and to determine whether these resources can elicit positive clinical outcomes for mothers and their infants.

\section{Author statements}

\section{Ethical approval}

This study received ethical approval from the CWIUH Research Ethic Committee and the Dublin Institute of Technology Research Ethics Committee.

\section{Funding}

This work was supported by the Dublin Institute of Technology Fiosraigh Scholarship awarded to DMA McCartney and RAK Kennedy.

\section{Competing interest}

None declared.

\section{Author contributions}

RAK Kennedy: 1) the conception and the design of the study, acquisition of data, analysis and interpretation of data, 2) drafting the article, 3) final approval of the version to be submitted.

L Mullaney: 1) the conception and the design of the study, 2) revising the article critically for important intellectual content, 3) final approval of the version to be submitted.

CME Reynolds: 1) analysis and interpretation of the data, 2) revising the article critically for important intellectual content, 3) final approval of the version to be submitted.

S Cawley 1) analysis and interpretation of the data, 2) revising the article critically for important intellectual content, 3) final approval of the version to be submitted.

MJ Turner: 1) the conception and the design of the study, 2) revising the article critically for important intellectual content, 3) final approval of the version to be submitted.

DMA McCartney: 1) the conception and the design of the study, analysis and interpretation of data 2) revising the article critically for important intellectual content, 3) final approval of the version to be submitted.

\section{R E F E R E N C E S}

1. Ramakrishnan U, Grant D, Goldenberg T, Zongrone A, Martorell R. Effect of Women's nutrition before and during early pregnancy on maternal and infant outcomes: a systematic review. Paediatr Perinat Epidemiol 2012;26(1):285-301.

2. Muhlhausler BS, Gugusheff JS, Ong ZY, Vithayathil MA. Pregnancy, obesity and insulin resistance: maternal overnutrition and the target windows of fetal development. Horm Mol Biol Clin Invest 2014;15(1):25-36.

3. Petry CJ. Gestational diabetes: risk factors and recent advances in its genetics and treatment. $\mathrm{Br} J$ Nutr 2010;104(6):775-87.

4. O'Sullivan EP, Avalos G, O'Reilly M, Dennedy MC, Gaffney G, Dunne F. Atlantic diabetes in pregnancy (DIP): the prevalence and outcomes of gestational diabetes mellitus using new diagnostic criteria. Diabetologia 2011;54(7):1670-5.

5. Haider BA, Olofin I, Wang M, Spiegelman D, Ezzati M, Fawzi WW, et al. Anaemia, prenatal iron use, and risk of adverse pregnancy outcomes: systematic review and metaanalysis. BMJ 2013;21. 346:f3443.

6. Cawley S, Mullaney L, McKeating A, Farren M, McCartney D, Turner MJ. An analysis of folic acid supplementation in women presenting for antenatal care. J Public Health (Oxf) 2015;38(1):112-9. 
7. McGowan A, McAulife FM. Maternal dietary patterns and associated nutrient intakes during each trimester of pregnancy. Public Health Nutr 2012;16(1):97-107.

8. Dunlevy F, Curran S, Harrington L, Culliney L. Recommendations for the clinical nutrition service of antenatal patients with diabetes - a summary report for the national diabetes working group. Irish Nutrition Dietetics Institute (INDI); 2011. Internal report.

9. Coombe Women and Infants University. Hospital annual clinical report. HSE Print and Design; 2014.

10. O'Brien OA, McCarthy M, Gibney ER, McAuliffe FM. Technology-supported dietary and lifestyle interventions in healthy pregnant women: a systematic review. Eur J Clin Nutr 2014;68(7):760-6.

11. Robroek SJ, Lindeboom DE, Burdorf A. Initial and sustained participation in an internet-delivered long-term worksite health promotion program on physical activity and nutrition. J Med Internet Res 2012;14(2):e43.

12. Mullaney L, O'Higgins A, Cawley S, Kennedy R, Mc Cartney D, Turner MJ. Websites and apps used by women to access infant feeding information. Proc Nutr Soc 2015;74(OCE4):e217.

13. O'Higgins A, Murphy OC, Egan A, Mullaney L, Sheehan S, Turner MJ. The use of digital media by women using the maternity services in a developed country. Ir Med J 2014;107(10):313-5.

14. Central Statistics Office EU Survey on Income and Living Conditions (EU-SILC) 2011 and revised 2010 results. Dublin: Central Statistics Office; 2013.

15. Peragallo Urrutia R, Berger AA, Ivins AA, Beckham AJ, Thorp Jr JM, Nicholson WK. Internet use and access among pregnant women via computer and mobile phones: implications for delivery of perinatal care. JMIR Mhealth Uhealth 2015;3(1):e25.

16. Moore JC, Stinson LL, Welniak EJ. Income measurement error in surveys: a review. J Off Stat 2000;16:331-61.

17. Moore J, Loomis LS. Reducing income nonresponse in a topic-based interview; 2001 May 17-20. Montreal, Candada. Paper Prepared for the 2001 AAPOR Meetings.

18. Huberty J, Dinkel D, Beets MW, Coleman J. Describing the use of the internet for health, physical activity, and nutrition information in pregnant women. Matern Child Health J 2013;17(8):1363-72.

19. Bensley RJ, Hovis A, Horton KD, Loyo JJ, Bensley KM, Phillips D, et al. Accessibility and preferred use of online Web applications among WIC participants with Internet access. J Nutr Educ Behav 2014;46(3):S87-92.

20. Lieffers JR, Vance VA, Hanning RM. Use of mobile device applications in Canadian dietetic practice. Can J Diet Pract Res 2014;75(1):41-7.

21. Institute of Obstetrics and Gynaecologists, Royal College of Physicians of Ireland and Clinical Strategy and Programmes
Directorate. Health Service Executive. Obesity and pregnancy - clinical practice guideline. Dublin: Health Service Executive; 2013.

22. Lagan BM, Sinclair M, Kernohan WG. Pregnant women's use of the internet: a review of published and unpublished evidence. Evid Based Midwifery 2006;4(1):17-23.

23. Eysenbach G, Kohler C. How do consumers search for and appraise health information on the world wide web? Qualitative study using focus groups, usability tests, and indepth interviews. BMJ 2002;324(7337):573-7.

24. Pew Internet \& American Life Project. How women and men use the internet. Washington, DC: Deborah Fallows; 2005.

25. Scullard P, Peacock C, Davies P. Googling children's health: reliability of medical advice on the internet. Arch Dis Child 2010;95(8):580-2.

26. Van Zutphen M, Milder IE, Bemelm WJ. Usage of an online healthy lifestyle program by pregnant women attending midwifery practices in Amsterdam. Prev Med 2008;46(6):552-7.

27. Mitchell MS, Faulkner GE. On supplementing "Foot in the door" incentives for eHealth program engagement. J Med Internet Res 2014;16(7):e179.

28. Borodulin K, Evenson KR, Herring AH. Physical activity patterns during pregnancy through postpartum. BMC Womens Health 2009;9:32.

29. Poudevigne MS, O'Connor PJ. A review of physical activity patterns in pregnant women and their relationship to psychological health. Sports Med 2006;36(1):19-38.

30. Baron R, Manniën J, Velde SJ, Klop T, Hutton EK, Brug J. Sociodemographic inequalities across a range of health status indicators and health behaviours among pregnant women in prenatal primary care: a cross-sectional study. BMC Pregnancy Childbirth 2015;15:261.

31. Kearney JM, Mc Cartney D, Mc Carthy S, Burke S, Knox B, Barton M. Food and nutrient intake and attitudes among disadvantaged groups on the island of Ireland [Internet]. Ireland: Safefood. Available from: www.safefood.eu/SafeFood/media/ SafeFoodLibrary/.../Kearney_Summary.pdf; 2008.

32. Bukman A, Teuscher D, Feskens EJM, Van Baak MA, Meershoek A, Jan Renes R. Perceptions on healthy eating, physical activity and lifestyle advice: opportunities for adapting lifestyle interventions to individuals with low socioeconomic status. BMC Public Health 2014;14:1036.

33. Winkler E, Turrell G. Confidence to cook vegetables and the buying habits of Australian households. J Am Diet Assoc 2009;109(10):1759-68.

34. Dunlevy F, Daly S, Turner MJ, Kinsley B. The Introduction of multidisciplinary structured group education for the treatment of gestational diabetes mellitus. In: Diabetes in pregnancy (DIP): diabetes, hypertension, metabolic syndrome and pregnancy; 2015 April 15-18. Germany. E-poster. 